\title{
Similar importance of edaphic and climatic factors for controlling soil organic carbon stocks of the world
}

\author{
Zhongkui Luo $^{1}$, Raphael A. Viscarra-Rosse ${ }^{2}$, and Tian Qian ${ }^{1}$ \\ ${ }^{1}$ College of Environmental and Resource Sciences, Zhejiang University, Hangzhou, Zhejiang 310058, China \\ ${ }^{2}$ Soil and Landscape Science, School of Molecular and Life Sciences, Curtin University, Perth, WA 6845, Australia
}

Correspondence: Zhongkui Luo (luozk@zju.edu.cn)

Received: 1 August 2020 - Discussion started: 11 August 2020

Revised: 2 February 2021 - Accepted: 15 February 2021 - Published: 22 March 2021

\begin{abstract}
Soil organic carbon (SOC) accounts for two-thirds of terrestrial carbon. Yet, the role of soil physicochemical properties in regulating SOC stocks is unclear, inhibiting reliable SOC predictions under land use and climatic changes. Using legacy observations from 141584 soil profiles worldwide, we disentangle the effects of biotic, climatic and edaphic factors (a total of 31 variables) on the global spatial distribution of SOC stocks in four sequential soil layers down to $2 \mathrm{~m}$. The results indicate that the 31 variables can explain $60 \%-70 \%$ of the global variance of SOC in the four layers, to which climatic variables and edaphic properties each contribute $\sim 35 \%$ except in the top $20 \mathrm{~cm}$ soil. In the top 0-20 cm soil, climate contributes much more than soil properties (43\% vs. $31 \%$ ), while climate and soil properties show the similar importance in the 20-50, 50-100 and 100$200 \mathrm{~cm}$ soil layers. However, the most important individual controls are consistently soil-related and include soil texture, hydraulic properties (e.g. field capacity) and $\mathrm{pH}$. Overall, soil properties and climate are the two dominant controls. Apparent carbon inputs represented by net primary production, biome type and agricultural cultivation are secondary, and their relative contributions were $\sim 10 \%$ in all soil depths. This dominant effect of individual soil properties challenges the current climate-driven framework of SOC dynamics and needs to be considered to reliably project SOC changes for effective carbon management and climate change mitigation.
\end{abstract}

\section{Introduction}

Soil organic carbon (SOC) represents the largest pool of terrestrial carbon (Le Quéré et al., 2016; Batjes, 2016) and plays a key role in combating climate change and ensuring soil productivity. To better manage land for maintaining SOC levels or enhancing carbon sequestration, it is vital to elucidate controlling factors of SOC stabilization and stock. As an important soil property, it is reasonable to expect that SOC might be integrally influenced by five predominant factors controlling soil development and formation - namely, climate, organisms, topography, parent materials and time (Jenny, 1941). However, climate is usually prioritized and considered to be critical (Carvalhais et al., 2014) because of its direct effect on soil carbon inputs via photosynthetic carbon assimilation and output via microbial decomposition. But climate-driven predictions of SOC dynamics (e.g. using Earth system models) remain largely uncertain, particularly across large extents (Todd-Brown et al., 2013; Bradford et al., 2016; Luo et al., 2017).

A primary source of the uncertainty is our poor understanding of how edaphic properties regulate SOC stabilization and stock in soil (Davidson and Janssens, 2006; Dungait et al., 2012). For example, SOC can be physically protected from decomposition via occlusion within soil aggregates and adsorption onto minerals (Six et al., 2000), which create physical barriers preventing microorganisms from decomposing carbon sources (Doetterl et al., 2015; Schimel and Schaeffer, 2012) regardless of climate conditions, but how this protection influences global SOC stocks is unclear. Additionally, the soil physicochemical environment controls the supply of water, nutrients, oxygen and other resources, which 
are required for microbial communities to utilize SOC as well as for plant carbon assimilation to replenish soil carbon pool. Considering the large spatial variability of soil properties globally, we need to understand the edaphic controls of SOC better. By explicitly considering the effect of soil physicochemical properties, we hope to promote a review of climate-driven frameworks of SOC dynamics.

In addition to our incomplete understanding of the general importance of soil properties in regulating SOC stocks, whether and how their effects vary with soil depth are also unclear. Most studies focus on topsoil layers (e.g. 0-30 cm), even though, globally, deeper soil layers (below $30 \mathrm{~cm}$ ) store more carbon than topsoils (Jobbágy and Jackson, 2000; Batjes, 2016). Like the topsoil SOC pool, the subsoil SOC pool may actively respond to climate and land use changes. Studies of whole-soil profiles have observed increased loss of subsoil SOC under warming (Pries et al., 2017; Melillo et al., 2017; Zhou et al., 2018) as well as under additional supply of fresh carbon (Fontaine et al., 2007). Land uses such as cropping and grazing can also induce substantial subsoil SOC loss (Sanderman et al., 2017), which is concerning because of the potential adverse effects of climate and land use changes. It is therefore imperative that we better understand the controlling factors of SOC in deep soil layers as this will help to develop unbiased strategies to effectively manage whole-soil profile carbon.

Here, we aim to disentangle the relative importance of climatic, biotic and edaphic controls on SOC stocks globally in different soil layers. To do so, we assessed data from 141584 whole-soil profiles across the globe including measurements of SOC and other soil physicochemical properties, collated by the World Soil Information Service (WoSIS) (Batjes et al., 2017). For each profile, 19 climate-related covariates reflecting seasonality, intra- and inter-annual variability of climate were obtained from the WorldClim database (Fick and Hijmans, 2017); the MODIS NPP (net primary productivity) product (Zhao and Running, 2010) was used to infer apparent carbon input into soil; and the MODIS land cover product (Friedl et al., 2010) was used to obtain land use information. Using these datasets, we disentangled the relative importance of biotic, climatic and edaphic covariates (a total of 31 variables, Table 1) in controlling the spatial variance in SOC stocks worldwide in four sequential soil layers (i.e. 0-20, 20$50,50-100$ and $100-200 \mathrm{~cm}$ ) and identified the correlations between SOC stock and the most important variables.

\section{Materials and methods}

\subsection{Observed soil profile data and harmonization}

The World Soil Information Service (WoSIS) collates and manages the largest database of explicit soil profile observations across the globe (Batjes et al., 2017) which forms the foundation of a series of digital soil mapping products such as the global SoilGrids (Hengl et al., 2017). The WoSIS dataset is still growing. When we visited the dataset last on 25 March 2019, there were a total of 141584 profiles which were used in this study. These profile observations were quality-assessed and standardized, using consistent procedures (Batjes et al., 2017). In each soil profile, multiple layers were sampled for determining SOC content and/or other soil properties. A total of 48 soil properties were recorded with multiple variates of the same property (e.g. pH measured in $\mathrm{H}_{2} \mathrm{O}, \mathrm{CaCl}_{2}, \mathrm{KCl}$ ). In the data assessment, we considered nine principal soil physicochemical properties other than SOC itself in the data analysis (Table 1). Taking the advantage of all measurements, however, other soil properties were used for missing data imputation (see the Sect. 2.2). The layer depths are inconsistent between soil profiles. We harmonized all soil properties including SOC to four standard depths (i.e. $0-20,20-50,50-100$ and $100-200 \mathrm{~cm}$ ) using mass-preserving splines (Bishop et al., 1999; Malone et al., 2009). This harmonization enables the calculation of SOC stock in the defined standard layers, making it possible to directly compare among soil profiles.

\subsection{SOC stock calculation and filling missing values}

We calculated SOC stock $\left(\mathrm{SOC}_{\mathrm{s}}, \mathrm{kg} \mathrm{C} \mathrm{m}^{-2}\right)$ in each standard depth as

$\mathrm{SOC}_{\mathrm{s}}=\frac{\mathrm{OC}}{100} \cdot D \cdot \mathrm{BD} \cdot\left(1-\frac{G}{100}\right)$,

where OC is the weight percentage SOC content in the fine earth fraction $<2 \mathrm{~mm}, D$ the soil depth (i.e. $0.2,0.3,0.5$ or $1 \mathrm{~m}$ in this study), BD the bulk density of the fine earth frac-

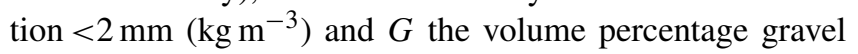
content ( $>2 \mathrm{~mm}$ ) of soil. Amongst the 141584 soil profiles, unfortunately, only 9672 profiles have all the measurements of OC, $D, \mathrm{BD}$ and $G$ to enable direct calculation of SOC stock. We call these profiles "stock profiles".

Another 82734 profiles have measured OC (i.e. the weight percentage SOC content), but BD and/or $G$ are missing. We call these profiles "content profiles". To utilize and take advantage of all OC measurements, we used generalized boosted regression modelling $(\mathrm{GBM})$ to perform imputations (i.e. fill missing data). As such, $\mathrm{SOC}_{\mathrm{s}}$ can be estimated. To do so, for BD and $G$ in each standard soil depth, GBM was developed based on all measurements of that property (e.g. BD) in the 141584 profiles with 32 other soil properties. Total carbon which includes organic and inorganic carbon and another nine soil properties (Table 1) which were used as predictors of SOC stocks were excluded as covariates (i.e. predictors). The final GBM model was validated using 10-fold cross validation repeated 10 times and applied to predict missing values of BD and G. A total of 92406 SOC profiles including stock profiles and content profiles with relevant measurements of nine soil properties (Table 1) was obtained and used to assess the effects of various variables on $\mathrm{SOC}_{\mathrm{S}}$ (Sect. 2.4). 
Table 1. Covariates used in the modelling of soil carbon stocks across the globe.

\begin{tabular}{|c|c|c|c|c|}
\hline Covariates & Code & Description & Unit & Data sources \\
\hline \multirow{9}{*}{$\begin{array}{l}\text { Soil } \\
\text { properties }\end{array}$} & TCEQ & Calcium carbonate content & $\mathrm{g} \mathrm{kg}^{-1}$ & \multirow[t]{9}{*}{ Batjes et al. (2017) } \\
\hline & ECEC & Effective cation exchange capacity & $\mathrm{cmol} \mathrm{kg}^{-1}$ & \\
\hline & ELCO & Electrical conductivity & $\mathrm{dS} \mathrm{m}^{-1}$ & \\
\hline & Clay & Clay content & $\%$ & \\
\hline & Sand & Sand content & $\%$ & \\
\hline & Silt & Silt content & $\%$ & \\
\hline & $\mathrm{pH}$ & $\mathrm{pH}$ measured in $\mathrm{H}_{2} \mathrm{O}$ & - & \\
\hline & LL15 & Lower limit obtained at a matric potential of $1500 \mathrm{kPa}$ & $\%$ & \\
\hline & DUL & Drained upper limit obtained at a matric potential of $33 \mathrm{kPa}$ & $\%$ & \\
\hline \multirow{19}{*}{$\begin{array}{l}\text { Climatic } \\
\text { variables }\end{array}$} & $T 1$ & Annual mean temperature & ${ }^{\circ} \mathrm{C}$ & \multirow{19}{*}{$\begin{array}{l}\text { WorldClim (Fick } \\
\text { and Hijmans, 2017) }\end{array}$} \\
\hline & $T 2$ & Mean diurnal range & ${ }^{\circ} \mathrm{C}$ & \\
\hline & $T 3$ & Isothermality $(T 2 / T 7 \times 100)$ & $\%$ & \\
\hline & $T 4$ & Temperature seasonality (standard deviation $\times 100$ ) & ${ }^{\circ} \mathrm{C}$ & \\
\hline & $T 5$ & Max temperature of warmest month & ${ }^{\circ} \mathrm{C}$ & \\
\hline & $T 6$ & Min temperature of coldest month & ${ }^{\circ} \mathrm{C}$ & \\
\hline & $T 7$ & Temperature annual range $(T 5-T 6)$ & ${ }^{\circ} \mathrm{C}$ & \\
\hline & $T 8$ & Mean temperature of wettest quarter & ${ }^{\circ} \mathrm{C}$ & \\
\hline & $T 9$ & Mean temperature of direst quarter & ${ }^{\circ} \mathrm{C}$ & \\
\hline & $T 10$ & Mean temperature of warmest quarter & ${ }^{\circ} \mathrm{C}$ & \\
\hline & $T 11$ & Mean temperature of coldest quarter & ${ }^{\circ} \mathrm{C}$ & \\
\hline & $P 1$ & Annual precipitation & $\mathrm{mm}$ & \\
\hline & $P 2$ & Precipitation of wettest month & $\mathrm{mm}$ & \\
\hline & $P 3$ & Precipitation of driest month & $\mathrm{mm}$ & \\
\hline & $P 4$ & Precipitation seasonality (coefficient of variation) & $\%$ & \\
\hline & $P 5$ & Precipitation of wettest quarter & $\mathrm{mm}$ & \\
\hline & $P 6$ & Precipitation of driest quarter & $\mathrm{mm}$ & \\
\hline & $P 7$ & Precipitation of warmest quarter & $\mathrm{mm}$ & \\
\hline & $P 8$ & Precipitation of coldest quarter & $\mathrm{mm}$ & \\
\hline \multirow[t]{3}{*}{ Other } & Biome & Biome type & - & $\begin{array}{l}\text { WWF (Olson et } \\
\text { al., 2001) }\end{array}$ \\
\hline & NPP & Net primary productivity & $\mathrm{kgC} \mathrm{m}^{-2} \mathrm{yr}^{-1}$ & $\begin{array}{l}\text { MODIS (Zhao and } \\
\text { Running, 2010) }\end{array}$ \\
\hline & Cultivation & Whether the land is cultivated (yes or no) & - & $\begin{array}{l}\text { MODIS (Friedl et } \\
\text { al., 2010) }\end{array}$ \\
\hline
\end{tabular}

These soil profiles cover 13 major biome groups although the profile numbers vary from 472 in flooded grasslands and savannas to 24382 in temperate broadleaf and mixed forests (Fig. 1). The profiles also cover various climate conditions across the globe with the mean annual temperature ranging from -19.6 to $30.7^{\circ} \mathrm{C}$ and mean precipitation ranging from 0 to $667.4 \mathrm{~cm} \mathrm{yr}^{-1}$ (Fig. 1). The prediction error of the GBM was propagated into the calculation of $\mathrm{SOC}_{\mathrm{s}}$ to account for uncertainty resulting from data imputation (see Sect. 2.4).

\subsection{Biotic and climatic covariates}

For each SOC profile, NPP was extracted from the MODIS NPP product (Zhao and Running, 2010). The NPP product includes the annual NPP from 2001 to 2015 at the resolution of $1 \mathrm{~km}^{2}$, which was estimated by analysing satel- lite data from MODIS using the global MODIS NPP algorithm (Zhao et al., 2005; Zhao and Running, 2010). NPP is the net carbon gained by plants (i.e. the difference between gross primary productivity and autotrophic respiration). If assuming a steady state of the vegetation (i.e. no long-term directional change of carbon biomass in plants), NPP will end up in soil via rhizodeposition and litter fall and will be equal to total carbon input into soil. Here we calculated the average NPP based on the data from 2001 to 2015 and called this average NPP the apparent carbon input to soil, acknowledging that not all ecosystems are at strict steady state, particularly those ecosystems (e.g. croplands) actively interacting with human activities. The WWF (World Wildlife Fund) map of the terrestrial ecoregions of the world (Olson et al., 2001; https://www.worldwildlife.org/ 


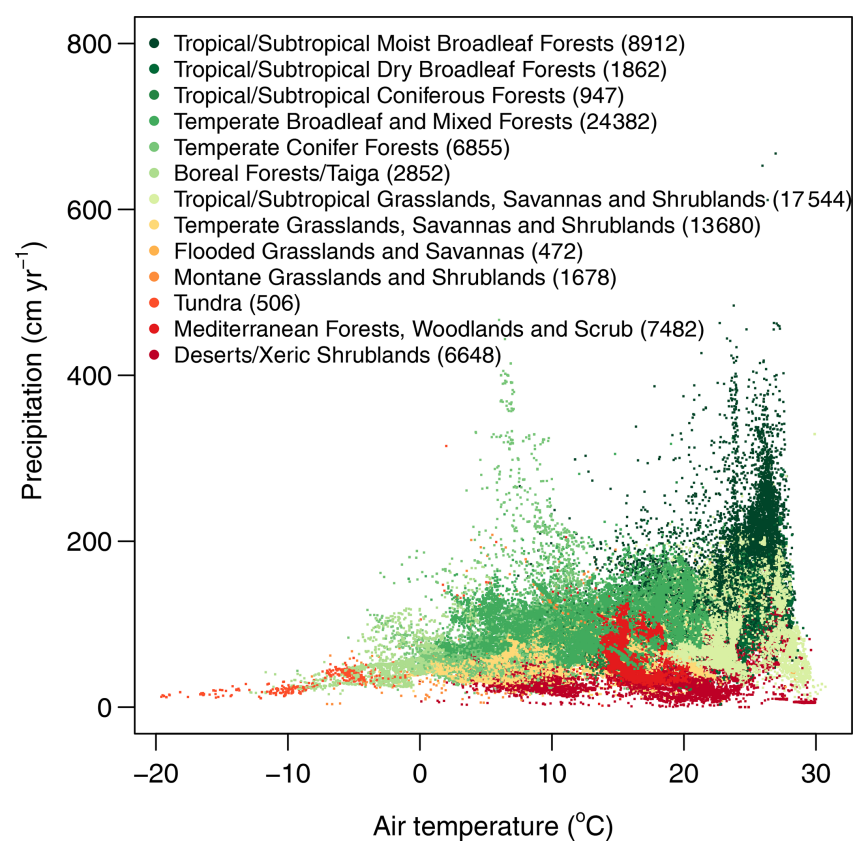

Figure 1. Distribution of soil profiles with soil carbon data in relation to mean annual air temperature and precipitation. Different colours show the biome type to which the soil profile belongs to. Numbers in parentheses show the number of soil profiles in the relevant biome. Some soil profiles (1382) were not included as climate and/or biome type could not be identified for them.

publications/terrestrial-ecoregions-of-the-world, last access: 18 March 2021) was used to extract the biome type for each location. The MODIS land cover map (Friedl et al., 2010) at the same resolution of NPP databases was used to identify whether or not the land is cultivated (i.e. land cover type of croplands and cropland/natural vegetation mosaic) at the location of each soil profile.

In addition to NPP, land cover and biome type, 19 climatic variables (Table 1) for each SOC profile were obtained from the WorldClim version 2 (Fick and Hijmans, 2017). The WorldClim version 2 calculates biologically meaningful variables using monthly temperature and precipitation during the period 1970-2000. The data at the same spatial resolution of the NPP data (i.e. $\sim 1 \mathrm{~km}^{2}$ ) were used in this study. Eleven of the 19 climatic variables are temperature-related (Table 1), and eight are precipitation-related (Table 1). These variables reflect the seasonality, intra- and inter-annual variability of climate, which would have both a direct (via decomposition thus carbon outputs from soil) and an indirect (via carbon assimilation thus carbon inputs to soil) effect on SOC stock.

\subsection{Data analysis}

A machine learning-based statistical model - boosted regression trees (BRTs) - was performed to explain the variability of $\mathrm{SOC}_{\mathrm{s}}$ across the globe and identify important controlling factors. A big advantage of the BRT model is its ability to model high-dimensional dataset, taking into account nonlinearities and interplay (Elith et al., 2008). Using the BRT model, we modelled $\mathrm{SOC}_{\mathrm{s}}$ in each standard depth as a function of edaphic variables in that depth, climatic and biotic variables (Table 1):

$\mathrm{SOC}_{\mathrm{s}}=f$ (edaphic, climatic, biome, NPP, cultivation).

We used a 10-fold cross validation to constrain the BRT model in R 3.6.1 (R Core Team, 2019) using algorithms implemented in the $\mathrm{R}$ package dismo. The amount of variance in $\mathrm{SOC}_{\mathrm{S}}$ explained by the model was assessed by the coefficient of determination $\left(R^{2}\right)$. To assess the potential uncertainty induced by the uneven distribution of soil profiles across the globe as well as the imputation of missing BD and $G$ for estimating $\mathrm{SOC}_{\mathrm{s}}$, we conducted 200 bootstrapping simulations (i.e. resample all soil profiles with replacement). For each bootstrap sample, $\mathrm{SOC}_{\mathrm{s}}$, if $\mathrm{BD}$ and $G$ are missing, was recalculated using BD and $G$ imputed by GBM plus an error randomly sampled from the distribution of imputation error. Using the new $\mathrm{SOC}_{\mathrm{s}}$ estimations, then, a new BRT model was fitted.

Considering the potential collinearity in the 19 climatic variables as well as in the nine soil properties, the BRT model was conducted using their principal components. That is, a principal component analysis (PCA) was performed to eliminate potential correlations in the soil and climatic variables, respectively. The important principal components (PCs) with variances of greater than 1 were retained in the BRT model based on Kaiser's criterion (Kaiser, 1960). The PCA was performed using the function prcomp in the package stats in R 3.6.1 (R Core Team, 2019). In addition, in order to demonstrate the importance of soil properties, we fitted another set of BRT models without soil properties. The model performance with and without soil properties were compared in terms of explaining the variance of SOC stocks across the globe.

The BRT model allows the estimation of the relative influence of each individual variable in predicting $\mathrm{SOC}_{\mathrm{s}}$, i.e. the percentage contribution of variables in the model. The relative influence is calculated based on the times a variable selected for splitting when growing a tree, weighted by squared model improvement due to that splitting, and then averaged over all fitted trees which were determined by the algorithm when adding more trees cannot reduce prediction residuals (Elith et al., 2008; Friedman and Meulman, 2003). As such, the larger the relative influence of a variable, the stronger the effect on $\mathrm{SOC}_{\mathrm{s}}$. In addition, we also calculated the $95 \%$ confidence intervals as the $2.5 \%$ and 97.5 quantiles of the relative influence estimated by 200 bootstrapping simulations, which represent the uncertainty in the importance of variables. To facilitate interpretation, the relative influence of each variable is scaled so that the sum of the influence of all variables is equal to 100 . The overall relative influences of 

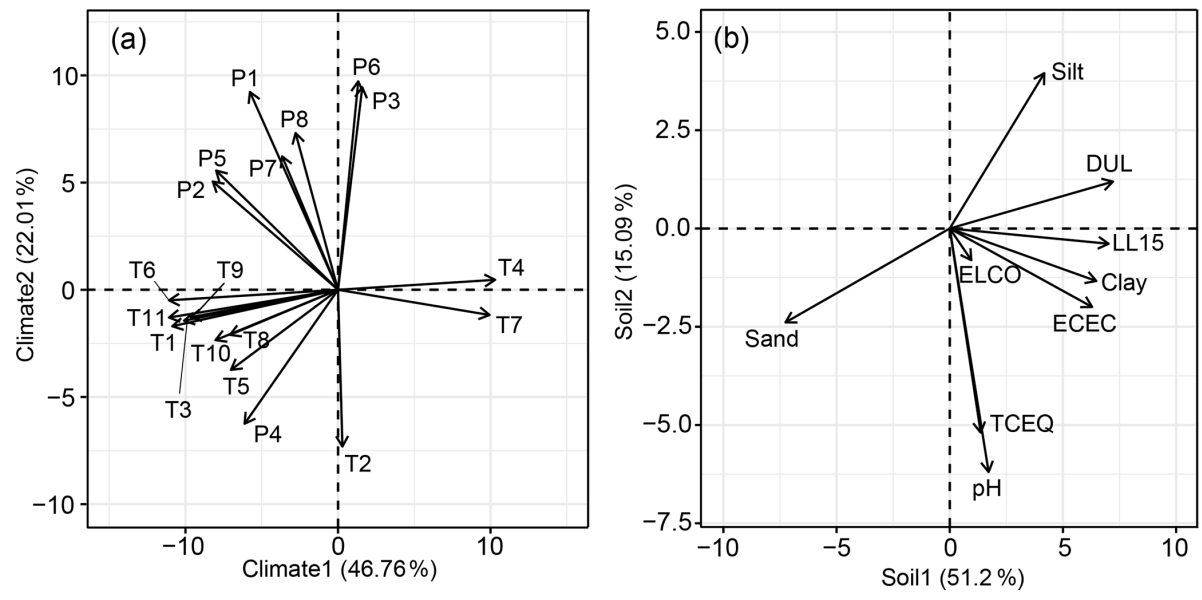

Figure 2. Loadings of 19 climatic variables (a) and nine soil properties (b) to the two most important principal components. $T 1$, annual mean temperature; $T 2$, mean diurnal range; $T 3$, isothermality; $T 4$, temperature seasonality; $T 5$, max temperature of warmest month; $T 6$, min temperature of coldest month; $T 7$, temperature annual range; $T 8$, mean temperature of wettest quarter; $T 9$, mean temperature of driest quarter; $T 10$, mean temperature of warmest quarter; $T 11$, mean temperature of coldest quarter; $P 1$, annual precipitation; $P 2$, precipitation of wettest month; $P 3$, precipitation of driest month; $P 4$, precipitation seasonality; $P 5$, precipitation of wettest quarter; $P 6$, precipitation of driest quarter; $P 7$, precipitation of warmest quarter; $P 8$, precipitation of coldest quarter. DUL, drained upper limit of soil; LL15, lower limit of soil; ELCO, electrical conductivity; ECEC, effective cation exchange capacity; TCEQ, calcium carbonate content; sand, silt and clay, the fraction of sand, silt and clay content of soil; $\mathrm{pH}$, soil $\mathrm{pH}$. See Table 1 for more details about the variables.

edaphic (i.e. the sum relative importance of all soil-related variables) and climatic (i.e. the sum relative importance of all climate-related variables) variables as well as biome type, NPP and cultivation were also calculated and compared. As we have 200 estimations (i.e. 200 bootstraps) of the relative influence, we calculated a weighted average relative influence for each variable with weights based on the $R^{2}$ of each BRT model.

\section{Results}

The 19 climatic variables could be represented by four principal components (PCs, i.e. Climate1-4, which were selected by Kaiser's criterion) which could explain $88 \%$ of their variance (Fig. 2; only the first two PCs were shown); and $72 \%$ of the variance in nine soil properties could be explained by three PCs (i.e. Soil1-3, Fig. 2). For Climate1-4, the most important contributing variables were $T 11$ (mean temperature of coldest quarter), $P 6$ (precipitation of driest quarter), $T 5$ (max temperature of warmest month) and $P 7$ (precipitation of warmest quarter), respectively. For Soil1-3, the most important contributing variables were sand content, $\mathrm{pH}$ and silt content, respectively (Fig. 2). Using Climate 1-4, NPP, biome type and cultivation as predictors, the BRT model could explain $53 \%, 46 \%, 42 \%$ and $49 \%$ of the variance of SOC stocks in the $0-20,20-50,50-100$ and $100-200 \mathrm{~cm}$ soil layers across the globe, respectively (Fig. 3). If Soil1-3 were included, an additional $18 \%, 18 \%, 20 \%$ and $13 \%$ of the variance could be explained in the four layers, respectively (Fig. 3). This result demonstrated that soil properties must be considered in order to explain the spatial variability of SOC stocks across the globe. However, it is noteworthy that the fitted model overestimated low SOC stocks and underestimated high SOC stocks. This bias of model performance at both ends of observed SOC stocks is common across all four depths (Fig. 3).

The results of the BRT model including soil properties (i.e. Soil1-3) indicated that Soill (i.e. the first PC of soil properties) was consistently the most important individual control of SOC stocks in the three deeper soil layers (i.e. 20-50, 50-100 and 100-200 cm; Fig. 4). On average, Soil1 alone contributed $21 \%$ (with $95 \%$ confidence intervals ranging from $17 \%-24 \%), 23 \%(20 \%-28 \%)$ and $22 \%(18 \%-$ $26 \%)$ to the explained variance of SOC stocks in the three deeper soil layers, respectively (Fig. 4). In the top $20 \mathrm{~cm}$ soil layer, Climate 2 was the most important, contributing $19 \%$ $(15 \%-23 \%)$ to the explained variance of SOC stocks, and Soil1 was the second most important and contributed $18 \%$ $(16 \%-20 \%)$. In the three deeper layers, the second most important contributors were NPP, biome type and Climate3, respectively (Fig. 4).

Summing the relative importance of individual variables, the overall effect of soil properties was relatively consistent among the four layers, accounting for $30 \%-40 \%$ of the overall influence of all assessed variables respectively, but they were more important in the deepest two layers than in the first top layer (Fig. 5). The overall relative influence of climate was significantly higher than that of soil in the top $20 \mathrm{~cm}$ soil layer (43\% vs. $31 \%$; Fig. 5). In the three deeper soil layers, the overall influences of climatic vari- 

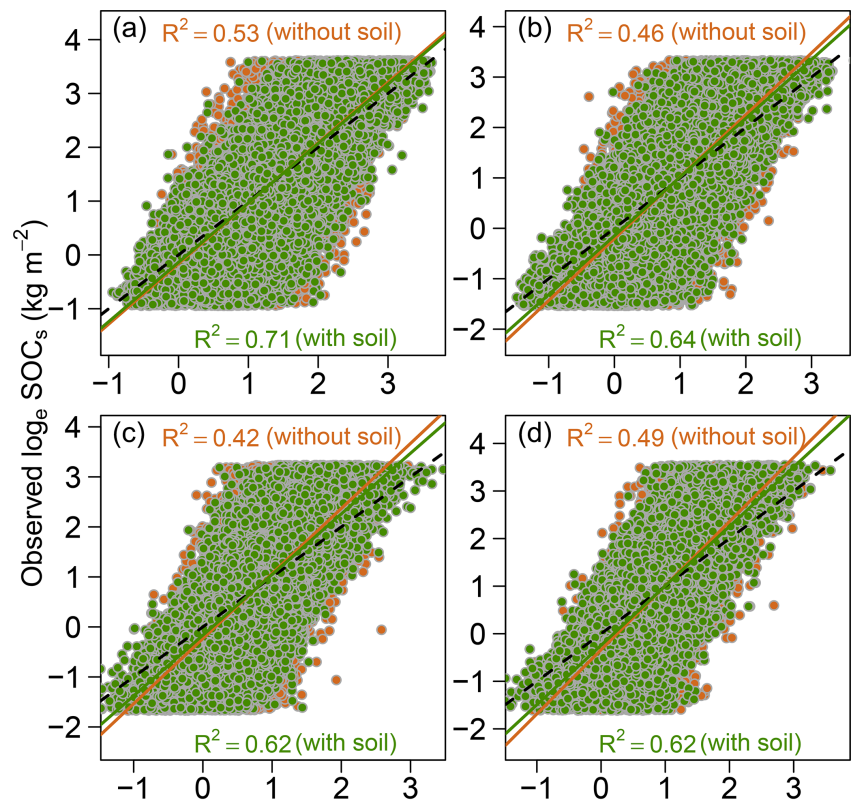

Predicted $\log _{\mathrm{e}} \mathrm{SOC}_{\mathrm{s}}\left(\mathrm{kg} \mathrm{m}^{-2}\right)$

Figure 3. An example of the performance of boosted regression trees in explaining soil organic carbon stocks in four standard soil depths across the globe. (a) $0-20 \mathrm{~cm}$, (b) $20-50 \mathrm{~cm}$, (c) $50-100 \mathrm{~cm}$ and (d) 100-200 cm. The data were natural-logarithm-transformed. The dashed line shows the $1: 1$ line. Chocolate and green circles show the results without and with predictors of soil properties, respectively.

ables and soil properties were comparable and did not show a significant difference. Overall, climatic variables accounted for $43 \%(38 \%-47 \%), 36 \%(32 \%-40 \%), 33 \%(28 \%-$ $37 \%)$ and $35 \%(31 \%-39 \%)$ in the four layers, respectively; and soil properties accounted for $30 \%(27 \%-33 \%), 35 \%$ $(30 \%-39 \%), 39 \%(35 \%-43 \%)$ and $37 \%(33 \%-41 \%)$, respectively (Fig. 5). The relevant influence of the remaining three variables (i.e. NPP, biome type and cultivation) was secondary and marginal $(\sim 10 \%$ in terms of relevant influence) compared to climate and soil variables and together accounted for the remaining $\sim 30 \%$ of the explained variance. With increasing soil depth, in general, the relevant influence of climate was decreased, while the influence of soil was increased. However, the overall influences of climate and soil remained relatively stable at the level of $70 \%$. These results demonstrate the comparable and primary effects of climate and soil properties on SOC stocks.

\section{Discussion}

\subsection{The importance of soil properties}

A series of soil properties may directly or indirectly affect SOC dynamic processes via influencing carbon inputs to soil, microbial activity and accessibility of carbon substrates to
Relative influence (\%)

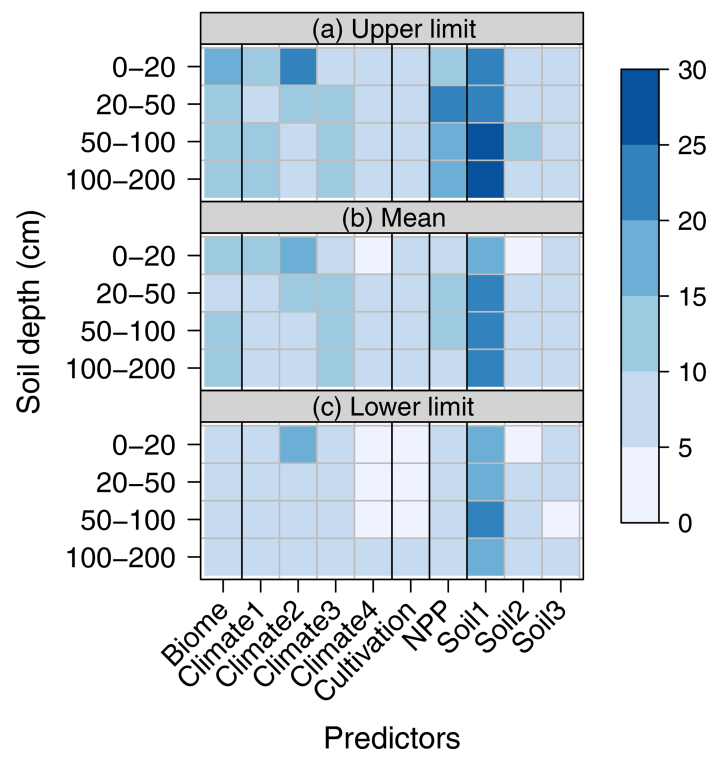

Figure 4. The relative influence of individual biotic, climatic and edaphic variables influencing global soil organic carbon stocks. Upper limit (a), mean (b) and lower limit (c) show the $97.5 \%$, average and $2.5 \%$ quantiles of 200 bootstrapping simulations, respectively. Biome, biome type; Climate1-4, the four most important principal components of 19 climatic variables; cultivation, whether or not the land is cultivated (yes or no); NPP, net primary production; Soil1-3, the three most important principal components of nine soil properties.

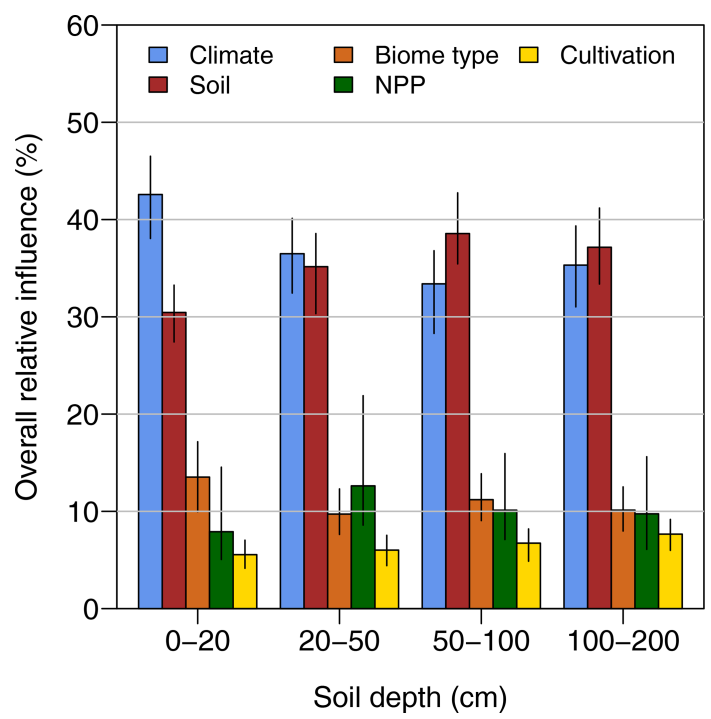

Figure 5. The overall relative influence of edaphic, climatic and biotic variables on soil organic carbon stocks in four soil depths across the globe. The overall relative influence for climate and soil is calculated as the sum of the relative influence of their individual variables (which is shown in Fig. 4). Error bars show the $95 \%$ confidence interval estimated based 200 bootstrapping simulations. 
microbes and thereby SOC stocks. Sand content (which is the most important contributor to the first PC of soil), for example, has significant effects on the formation and transformation of soil aggregates which regulate the stability of SOC as well as soil porosity and thereby oxygen availability for microbial decomposition of SOC (Dungait et al., 2012; Six et al., 2002). In addition, soil properties such as LL15 and DUL have dominant control over soil water dynamics, which further influence water availability for plant growth. Theoretically, LL15 is close to the permanent plant wilting point; it thus may strongly regulate plant growth therefore carbon inputs into soil and final SOC stocks. Together with DUL (i.e. drained upper limit - soil water content obtained at the matric potential of $33 \mathrm{kPa}$ ), LL15 determines the available water capacity of soil (AWC, i.e. the difference between DUL and LL15), and thus LL15 would affect SOC stock via its determination on soil AWC, while AWC couples with a series of soil hydrological processes such as runoff and drainage, which have direct effects on the vertical/horizontal translocation of SOC (Luo et al., 2020; Kaiser and Kalbitz, 2012). Soil properties are more important for controlling SOC stocks in deeper layers than in upper layers. This phenomenon may be due to the fact that soil structure may have substantial effects on water and oxygen diffusion in deeper layers. Potentially more frequent waterlogging and low oxygen in subsoil result in additional environmental constraints inhibiting microbial decomposition of SOC (Huang et al., 2020).

Our results demonstrate the primary control of soil properties on SOC stocks in the whole-soil profile across the globe. Indeed, the results suggested that soil-related principal components were consistently the most important individual influential variables in three deeper soil layers except in the assessed $0-20 \mathrm{~cm}$ soil layer. Soil physical and chemical properties directly determine the activity of the decomposer community which mediates the decomposition of soil carbon (Derrien et al., 2014; Foesel et al., 2014; Bernard et al., 2012). More importantly, soil carbon can be physically protected from decomposition via occlusion with soil aggregates and binding with minerals (Lehmann and Kleber, 2015; Dungait et al., 2012; Schmidt et al., 2011), while the protection capacity is largely determined by soil physicochemical properties (Six et al., 2000). These physical protection processes may lead to soil-dependent stabilization/destabilization of different soil carbon substrates (Waldrop and Firestone, 2004; Keiluweit et al., 2015; Six et al., 2002). However, it should be noted that complex interplays of various soil properties are involved in SOC stabilization and destabilization processes. It is also difficult to obtain a cause-effect conclusion on the relationship between a particular soil physicochemical property and SOC stocks.

\subsection{The importance of climate}

Few studies have paid particular attention to the dynamics of SOC in subsoils across large scales. One might expect greater importance of climate in surface soils as topsoil is at the frontline of the interaction with the atmosphere. But our results do not show a clearly decreasing importance of climate with soil depth. Rather, the overall influence of climatic variables on SOC stocks is statistically similar in all soil layers. In a forest soil, a recent study found that SOC in the whole-soil profile down to $1 \mathrm{~m}$ is sensitive to warming (Pries et al., 2017). This sensitivity may be general across the globe. However, it is noteworthy that neither mean annual temperature nor mean annual precipitation was the most important individual climatic variable. Rather, climatic variables reflecting seasonal variability were more important. This result may suggest that, except for average change trend, it is important to understand the change patterns of temperature and precipitation under climate change. For example, a number of studies have demonstrated that extreme climate events (e.g. drought and heatwaves) have significant effects on the carbon cycle, including soil carbon, due to their dramatic influence on the transport and availability of water and energy as well as ecosystem functional processes (Reichstein et al., 2013). Field observations, particularly via manipulative experiments of whole-soil profile, are certainly needed to detect how deep soil carbon responds to climate change as the result may have significant implications on the fate of deep soil carbon under future climatic conditions.

\subsection{Secondary role of carbon inputs in determining spatial variability of SOC stocks}

The effect of apparent carbon input, NPP, on SOC stock is generally small in all assessed soil layers (Fig. 5). This result is in line with findings from a continental-scale study across sub-Saharan Africa where climate and geochemistry are more important predictors of SOC content than aboveground carbon inputs (von Fromm et al., 2020). The importance of NPP may largely depend on how much NPP ends up in the soil and how it is translocated to different depths (Wang et al., 2021). Total NPP may not be a useful indicator of actual carbon inputs into different soil depths, particularly in deeper layers. Cultivation, for example, may substantially change the fate of plant biomass - a large fraction of plant biomass may be harvested as yield or consumed by livestock and thus does not contribute to soil carbon. This could explain the phenomena that cultivation (cultivated vs. non-cultivated in this study) and NPP show the similar importance in general. In addition, the final importance of carbon inputs may also depend on their quality (e.g. carbon-tonitrogen ratio), while NPP alone does not bring such information. The quality of carbon inputs represented by their nutrient content and chemical structure plays a vital role in SOC formation and transformation (Hessen et al., 2004; Jastrow et al., 2007). In our study, biome type (which shows similar importance to NPP) would partially reflect the importance of carbon input quality as different biome types have distinct carbon biomass quality (e.g. wood vs. leaf litter, which 
are the main component of NPP). However, here we must to point out that the minor role of carbon inputs in determining the global spatial distribution of SOC stocks does not mean that they are not important for local carbon management. Under the same climatic and edaphic conditions, indeed, carbon inputs should be the predominant factor controlling if the soil is a carbon sink or source (Luo et al., 2017).

\subsection{Limitations and future research}

Although we have used a diverse and representative dataset across the globe for the analysis, there are still some limitations in the datasets and assessment. First, our study did not bring detailed land use history and intensity (such as the time length of cropping and the intensity of grazing) into the analysis, which may significantly affect SOC stabilization processes and thus SOC stocks in managed landscapes (Sanderman et al., 2017). As anthropogenic land use may change from year to year, it is challenging to accurately explain SOC stock changes in those systems that experience intensive human disturbances across large extents. Second, all soil properties including SOC were treated as constant. In reality, however, some soil properties, particularly chemical variables such as $\mathrm{pH}$, may actively respond to external disturbance including human activities. Treating these variables as constant may result in under- or overestimations of the variable importance if a variable shows marked temporal variability. Third, in managed systems, the apparent carbon input represented by NPP may not accurately reflect the real carbon input into soil (Luo et al., 2018; Pausch and Kuzyakov, 2018) as discussed above, leading to biased estimation of the importance of $\mathrm{C}$ inputs. In cropping areas, for example, yield harvesting and crop residue removal certainly reduce the fraction of NPP ending up in the soil. Fourth, we would like to point out that, albeit edaphic factors appear to be the dominant individual controls on SOC stock, climate might have an impact on those edaphic factors and hence SOC stocks in the long term (Jenny, 1941). Indeed, Luo et al. (2017) have provided evidence that climate not only directly but also indirectly (via its effect on edaphic factors) exerts significant effect on SOC dynamics. All these limitations should be overcome to provide more robust predictions on the role of different factors in SOC stabilization and stock, which will be particularly important for understanding long-term SOC dynamics in managed systems. Fourth, we would like to note that this study focused on the controls over the global spatial pattern of SOC stocks and did not explicitly assess the potential variability of controls at small scales. Under different land use types, for example, factors controlling SOC stock would change. A recent study focused on SOC component fractions has found that continental drivers of SOC stocks were modulated by regional environmental factors (Viscarra Rossel et al., 2019). In order to better understand regional-scale factors controlling SOC dynamics, we should further explore the controls over different spatial scales. Considering that we only included limited soil properties in our assessment and different soil properties may play different roles at different scales, scale-dependent understanding of controls over SOC stocks is important to make site-specific management practices for sustainable soil use and carbon management. Finally, soil samples are still limited in some areas (e.g. tundra and flooded grasslands and savannas) (Batjes, 2016). We do not know much about whether some of the relationships we find between SOC stocks and predictor variables are universal or maybe fundamentally different in less studied soils. The uneven distribution of soil samples may also help to explain the model bias in explaining low and high SOC stocks (Fig. 3). Our results indicate that there are large uncertainties in the relative importance of climate and soil depending on the data used to fit the model (Fig. 5).

\section{Conclusions}

Quantitatively, we have demonstrated the primary role of soil properties together with climate in regulating SOC stock in the whole-soil profile across the globe. This result has important implications for understanding mechanisms of SOC stabilization and destabilization. Previous modelling and experimental efforts have mostly focused on climatic and biotic aspects, and many of the studies are over smaller scales. We argue that soil physicochemical characteristics define the boundary conditions for the climatic and biotic factors. That is, climatic and biotic factors (e.g. carbon inputs) can regulate the rate of SOC of shifting from one capacity to another, but a soil's physicochemical properties (e.g. soil structure) may inherently determine the SOC stock capacity of soil. It is thus critical to understand how soil processes mediated by different soil properties in different soil layers respond to those climatic and biotic factors and land management practices and feed this information into the prediction of SOC stock capacity in the whole-soil profile. However, individual soil variables work together involving complex interactions and nonlinear relationships with each other as well as with climate to regulate SOC stock (Figs. 2 and 4). We need more and better quality data (e.g. following the same soil sampling and measuring procedure and using a novel approach for monitoring of soil properties) and innovative methods (Viscarra Rossel et al., 2017) for representing soil heterogeneity to facilitate robust prediction of SOC dynamics over large extents. Results of this study further demonstrate that globally the influence of individual climatic variables on SOC stock is weaker than the influence of individual soil properties regardless of soil depth. Current Earth system models are mostly driven by climate, with few cases having approximated the regulation of soil properties on carbon stabilization and destabilization (Tang and Riley, 2014; Riley et al., 2014). Undoubtedly, climate has direct effect on plant growth and thus potential carbon inputs to the soil, but our results demonstrate that soil properties are also primary controls of global SOC stocks. 
Our research highlights the urgent need to consider soil properties and their interactions with climate to provide more reliable predictions of SOC stock and changes under climatic and land use changes.

Code availability. Code used to generate the results in this study can be reasonably requested from the corresponding author.

Data availability. Soil data including soil organic carbon and the considered soil properties from WoSIS are available at http://www. isric.org/explore/wosis/accessing-wosis-derived-datasets, last access: 18 March 2021. Climate data including 19 bioclimatic variables from WorldClim are available at https://www.worldclim.org/ data/worldclim21.html, last access: 18 March 2021.

Author contributions. ZL conceived the study and assessed the data; ZL interpreted the results and wrote the manuscript with the contribution of RAVR; TQ contributed to data assessment and creating figures.

Competing interests. The authors declare that they have no conflict of interest.

Acknowledgements. We thank the people who originally collected the data and made this invaluable data publicly available.

Financial support. This research has been supported by the National Natural Science Foundation of China (grant no. 41930754), Fundamental Research Funds for the Central Universities (grant no. 2020FZZX001-06), and Research Innovation Foundation for Young Scholars (grant no. K20200203).

Review statement. This paper was edited by Michael Bahn and reviewed by two anonymous referees.

\section{References}

Batjes, N. H.: Harmonized soil property values for broad-scale modelling (WISE30sec) with estimates of global soil carbon stocks, Geoderma, 269, 61-68, 2016.

Batjes, N. H., Ribeiro, E., van Oostrum, A., Leenaars, J., Hengl, T., and Mendes de Jesus, J.: WoSIS: providing standardised soil profile data for the world, Earth Syst. Sci. Data, 9, 1-14, https://doi.org/10.5194/essd-9-1-2017, 2017.

Bernard, L., Chapuis-Lardy, L., Razafimbelo, T., Razafindrakoto, M., Pablo, A. L., Legname, E., Poulain, J., Bruls, T., O’Donohue, M., Brauman, A., Chotte, J. L., and Blanchart, E.: Endogeic earthworms shape bacterial functional communities and affect organic matter mineralization in a tropical soil, ISME J., 6, 213222,2012
Bishop, T., McBratney, A., and Laslett, G.: Modelling soil attribute depth functions with equal-area quadratic smoothing splines, Geoderma, 91, 27-45, 1999.

Bradford, M. A., Wieder, W. R., Bonan, G. B., Fierer, N., Raymond, P. A., and Crowther, T. W.: Managing uncertainty in soil carbon feedbacks to climate change, Nat. Clim. Change, 6, 751-758, 2016.

Carvalhais, N., Forkel, M., Khomik, M., Bellarby, J., Jung, M., Migliavacca, M., Mingquan, M., Saatchi, S., Santoro, M. Thurner, M., Weber, U., Ahrens, B., Beer, C., Cescatti, A., Randerson, J. T., and Reichstein, M.: Global covariation of carbon turnover times with climate in terrestrial ecosystems, Nature, 514, 213-217, 2014.

Davidson, E. A. and Janssens, I. A.: Temperature sensitivity of soil carbon decomposition and feedbacks to climate change, Nature, 440, 165-173, https://doi.org/10.1038/nature04514, 2006.

Derrien, D., Plain, C., Courty, P. E., Gelhaye, L., MoerdijkPoortvliet, T. C. W., Thomas, F., Versini, A., Zeller, B., Koutika, L. S., Boschker, H. T. S., and Epron, D.: Does the addition of labile substrate destabilise old soil organic matter?, Soil Biol. Biochem., 76, 149-160, 2014.

Doetterl, S., Stevens, A., Six, J., Merckx, R., van Oost, K., Pinto, M. C., Casanova-Katny, A., Muñoz, C., Boudin, M., and Venegas, E. Z.: Soil carbon storage controlled by interactions between geochemistry and climate, Nat. Geosci., 8, 780-783, https://doi.org/10.1038/ngeo2516, 2015.

Dungait, J. A. J., Hopkins, D. W., Gregory, A. S., and Whitmore, A. P.: Soil organic matter turnover is governed by accessibility not recalcitrance, Global Change Biol., 18, 1781-1796, 2012.

Elith, J., Leathwick, J. R., and Hastie, T.: A working guide to boosted regression trees, J. Anim. Ecol., 77, 802-813, 2008.

Fick, S. E. and Hijmans, R. J.: WorldClim 2: new $1 \mathrm{~km}$ spatial resolution climate surfaces for global land areas, Int. J. Climatol., 37, 4302-4315, https://doi.org/10.1002/joc.5086, 2017.

Foesel, B. U., Nagele, V., Naether, A., Wust, P. K., Weinert, J., Bonkowski, M., Lohaus, G., Polle, A., Alt, F., Oelmann, Y., Fischer, M., Friedrich, M. W., and Overmann, J.: Determinants of Acidobacteria activity inferred from the relative abundances of 16S rRNA transcripts in German grassland and forest soils, Environ. Microbiol., 16, 658-675, 2014.

Fontaine, S., Barot, S., Barré, P., Bdioui, N., Mary, B., and Rumpel, C.: Stability of organic carbon in deep soil layers controlled by fresh carbon supply, Nature, 450, 277-280, 2007.

Friedl, M. A., Sulla-Menashe, D., Tan, B., Schneider, A., Ramankutty, N., Sibley, A., and Huang, X.: MODIS Collection 5 global land cover: Algorithm refinements and characterization of new datasets, Remote Sens. Environ., 114, 168-182, 2010.

Friedman, J. H. and Meulman, J. J.: Multiple additive regression trees with application in epidemiology, Stat. Med., 22, 13651381, 2003.

Hengl, T., Mendes de Jesus, J., Heuvelink, G. B., Gonzalez, M. R., Kilibarda, M., Blagotić, A., Shangguan, W., Wright, M. N., Geng, X., and Bauer-Marschallinger, B.: SoilGrids250m: Global gridded soil information based on machine learning, PLoS One, 12, e0169748, https://doi.org/10.1371/journal.pone.0169748, 2017.

Hessen, D. O., Ågren, G. I., Anderson, T. R., Elser, J. J., and De Ruiter, P. C.: Carbon sequestration in ecosystems: the role of stoichiometry, Ecology, 85, 1179-1192, 2004. 
Huang, W., Ye, C., Hockaday, W. C., and Hall, S. J.: Trade-offs in soil carbon protection mechanisms under aerobic and anaerobic conditions, Global Change Biol., 26, 3726-3737, 2020.

Jastrow, J. D., Amonette, J. E., and Bailey, V. L.: Mechanisms controlling soil carbon turnover and their potential application for enhancing carbon sequestration, Climatic Change, 80, 5-23, 2007.

Jenny, H.: Factors of soil formation, a system of quantitative pedology, McGraw-Hill, New York, USA, 300 pp., 1941.

Jobbágy, E. G. and Jackson, R. B.: The vertical distribution of soil organic carbon and its relation to climate and vegetation, Ecol. Appl., 10, 423-436, 2000.

Kaiser, H. F.: The application of electronic computers to factor analysis, Educat. Psychol. Meas., 20, 141-151, 1960.

Kaiser, K. and Kalbitz, K.: Cycling downwards - dissolved organic matter in soils, Soil Biol. Biochem., 52, 29-32, 2012.

Keiluweit, M., Bougoure, J. J., Nico, P. S., Pett-Ridge, J., Weber, P. K., and Kleber, M.: Mineral protection of soil carbon counteracted by root exudates, Nat. Clim. Change, 5, 588-595, 2015.

Le Quéré, C., Andrew, R. M., Canadell, J. G., Sitch, S., Korsbakken, J. I., Peters, G. P., Manning, A. C., Boden, T. A., Tans, P. P., Houghton, R. A., Keeling, R. F., Alin, S., Andrews, O. D., Anthoni, P., Barbero, L., Bopp, L., Chevallier, F., Chini, L. P., Ciais, P., Currie, K., Delire, C., Doney, S. C., Friedlingstein, P., Gkritzalis, T., Harris, I., Hauck, J., Haverd, V., Hoppema, M., Klein Goldewijk, K., Jain, A. K., Kato, E., Körtzinger, A., Landschützer, P., Lefèvre, N., Lenton, A., Lienert, S., Lombardozzi, D., Melton, J. R., Metzl, N., Millero, F., Monteiro, P. M. S., Munro, D. R., Nabel, J. E. M. S., Nakaoka, S., O'Brien, K., Olsen, A., Omar, A. M., Ono, T., Pierrot, D., Poulter, B., Rödenbeck, C., Salisbury, J., Schuster, U., Schwinger, J., Séférian, R., Skjelvan, I., Stocker, B. D., Sutton, A. J., Takahashi, T., Tian, H., Tilbrook, B., van der Laan-Luijkx, I. T., van der Werf, G. R., Viovy, N., Walker, A. P., Wiltshire, A. J., and Zaehle, S.: Global Carbon Budget 2016, Earth Syst. Sci. Data, 8, 605-649, https://doi.org/10.5194/essd-8-605-2016, 2016.

Lehmann, J. and Kleber, M.: The contentious nature of soil organic matter, Nature, 528, 60-68, 2015.

Luo, Z., Wang, E., Feng, W., Luo, Y., and Baldock, J.: The importance and requirement of belowground carbon inputs for robust estimation of soil organic carbon dynamics: Reply to Keel et al. (2017), Global Change Biol., 24, 397-398, 2018.

Luo, Z., Luo, Y., Wang, G., Xia, J., and Peng, C.: Warming-induced global soil carbon loss attenuated by downward carbon movement, Global Change Biol., 26, 7242-7254, 2020.

Luo, Z. K., Feng, W. T., Luo, Y. Q., Baldock, J., and Wang, E. L.: Soil organic carbon dynamics jointly controlled by climate, carbon inputs, soil properties and soil carbon fractions, Global Change Biol., 23, 4430-4439, 2017.

Malone, B. P., McBratney, A., Minasny, B., and Laslett, G.: Mapping continuous depth functions of soil carbon storage and available water capacity, Geoderma, 154, 138-152, 2009.

Melillo, J. M., Frey, S. D., DeAngelis, K. M., Werner, W. J., Bernard, M. J., Bowles, F., Pold, G., Knorr, M., and Grandy, A.: Long-term pattern and magnitude of soil carbon feedback to the climate system in a warming world, Science, 358, 101-105, 2017.

Olson, D. M., Dinerstein, E., Wikramanayake, E. D., Burgess, N. D., Powell, G. V. N., Underwood, E. C., D’ Amico, J. A., Itoua, I.,
Strand, H. E., Morrison, J. C., Loucks, C. J., Allnutt, T. F., Ricketts, T. H., Kura, Y., Lamoreux, J. F., Wettengel, W. W., Hedao, P., and Kassem, K. R.: Terrestrial ecoregions of the world: a new map of life on Earth, Bioscience, 51, 933-938, 2001.

Pausch, J. and Kuzyakov, Y.: Carbon input by roots into the soil: Quantification of rhizodeposition from root to ecosystem scale, Global Change Biol., 24, 1-12, 2018.

Pries, C. E. H., Castanha, C., Porras, R., and Torn, M.: The wholesoil carbon flux in response to warming, Science, 355, 1420 1423, 2017.

$\mathrm{R}$ Core Team: A language and environment for statistical computing, R Foundation for Statistical Computing, Vienna, Austria, 2019.

Reichstein, M., Bahn, M., Ciais, P., Frank, D., Mahecha, M. D., Seneviratne, S. I., Zscheischler, J., Beer, C., Buchmann, N., Frank, D. C., Papale, D., Rammig, A., Smith, P., Thonicke, K., van der Velde, M., Vicca, S., Walz, A., and Wattenbach, M.: Climate extremes and the carbon cycle, Nature, 500, 287-295, 2013.

Riley, W. J., Maggi, F., Kleber, M., Torn, M. S., Tang, J. Y., Dwivedi, D., and Guerry, N.: Long residence times of rapidly decomposable soil organic matter: application of a multi-phase, multi-component, and vertically resolved model (BAMS1) to soil carbon dynamics, Geosci. Model Dev., 7, 1335-1355, https://doi.org/10.5194/gmd-7-1335-2014, 2014.

Sanderman, J., Hengl, T., and Fiske, G. J.: Soil carbon debt of 12000 years of human land use, P. Natl. Acad. Sci. USA, 114, 9575-9580, 2017.

Schimel, J. P. and Schaeffer, S. M.: Microbial control over carbon cycling in soil, Front. Microbiol., 3, 348, https://doi.org/10.3389/fmicb.2012.00348, 2012.

Schmidt, M. W. I., Torn, M. S., Abiven, S., Dittmar, T., Guggenberger, G., Janssens, I. A., Kleber, M., Kogel-Knabner, I., Lehmann, J., Manning, D. A. C., Nannipieri, P., Rasse, D. P., Weiner, S., and Trumbore, S. E.: Persistence of soil organic matter as an ecosystem property, Nature, 478, 49-56, 2011.

Six, J., Elliott, E. T., and Paustian, K.: Soil macroaggregate turnover and microaggregate formation: a mechanism for $\mathrm{C}$ sequestration under no-tillage agriculture, Soil Biol. Biochem., 32, 2099-2103, 2000.

Six, J., Conant, R. T., Paul, E. A., and Paustian, K.: Stabilization mechanisms of soil organic matter: Implications for C-saturation of soils, Plant Soil, 241, 155-176, 2002.

Tang, J. and Riley, W. J.: Weaker soil carbon-climate feedbacks resulting from microbial and abiotic interactions, Nat. Clim. Change, 5, 56-60, https://doi.org/10.1038/nclimate2438, 2014.

Todd-Brown, K. E. O., Randerson, J. T., Post, W. M., Hoffman, F. M., Tarnocai, C., Schuur, E. A. G., and Allison, S. D.: Causes of variation in soil carbon simulations from CMIP5 Earth system models and comparison with observations, Biogeosciences, 10, 1717-1736, https://doi.org/10.5194/bg-10-1717-2013, 2013.

Viscarra Rossel, R. A., Lobsey, C. R., Sharman, C., Flick, P., and McLachlan, G.: Novel proximal sensing for monitoring soil organic C stocks and condition, Environ. Sci. Technol., 51, 56305641, 2017.

Viscarra Rossel, R. A., Lee, J., Behrens, T., Luo, Z., Baldock, J., and Richards, A.: Continental-scale soil carbon composition and vulnerability modulated by regional environmental controls, Nat. Geosci., 12, 547-552, https://doi.org/10.1038/s41561-019-0373z, 2019. 
von Fromm, S. F., Hoyt, A. M., Acquah, G. E., Aynekulu, E., Berhe, A. A., Haefele, S. M., Lange, M., McGrath, S. P., Shepherd, K. D., Sila, A. M., Six, J., Towett, E. K., Trumbore, S. E., Vågen, T.-G., Weullow, E., Winowiecki, L. A., and Doetterl, S.: Continental-scale controls on soil organic carbon across sub-Saharan Africa, SOIL Discuss. [preprint], https://doi.org/10.5194/soil-2020-69, in review, 2020.

Waldrop, M. P. and Firestone, M. K.: Altered utilization patterns of young and old soil $\mathrm{C}$ by microorganisms caused by temperature shifts and $\mathrm{N}$ additions, Biogeochemistry, 67, 235-248, 2004.

Wang, G., Xiao, L., Mao, X., Guo, X., Cowie, A., Zhang, S., Wang, M., Chen, S., Zhang, G., Shi, Z., and Luo, Z.: Most root-derived carbon inputs do not contribute to the global bulk soil carbon pool, Research Square [preprint], https://doi.org/10.21203/rs.3.rs-65178/v1, in review, 2021.
Zhao, M. and Running, S. W.: Drought-Induced Reduction in Global Terrestrial Net Primary Production from 2000 Through 2009, Science, 329, 940-943, 2010.

Zhao, M., Heinsch, F. A., Nemani, R. R., and Running, S. W.: Improvements of the MODIS terrestrial gross and net primary production global data set, Remote Sens. Environ., 95, 164-176, 2005.

Zhou, X., Xu, X., Zhou, G., and Luo, Y.: Temperature sensitivity of soil organic carbon decomposition increased with mean carbon residence time: Field incubation and data assimilation, Global Change Biol., 24, 810-822, 2018. 